\title{
The Cycles of Phosphorus and Nitrogen in Tokyo Bay
}

\author{
Yoshihiro Matida \\ (Freshwater Fisheries Research Laboratory)
}

Theoretical treatment of the distribution and seasonal changes in the contents of nitrogen and phosphorus have generally been limited to the case of oceanic water. The similar treatment, however, is difficult in the case of coastal water. The difficulties may probably be due to the facts that the coastal water is rich in organic matter and that a condiderable part of it is in the form of dissolved organic substances.

- Some explanations on the seasonal changes in the contents of nutrient salts in Tokyo Bay have been forwarded from the results that the nitrogen phosphorus ratio in such waters was found to be the same as that in oceanic water.

\section{Results and Discussions}

According to Suda (1929), Tokyo Bay is divided into two regions from hydrography and geography; The inner part, north of Kannonsaki-Futtusaki line, and the outer pârt, called Uraga Suido, the region within the two lines Zyogashima- Sunosaki and Kannonsaki_- Futtusaki (Fig. 1). The area, volume, and average depth of the former are $1,187 \mathrm{~km}^{2},, 16.6 \mathrm{~km}^{3}$., and $13.9 \mathrm{~m}$., respectively, and those of the latter are $467 \mathrm{~km}^{2}, 71 \mathrm{~km}^{3}$, and $152 \mathrm{~m}$., respectively. From Fig. 2, prepared from the data obtained by monthly observations (Central Fisheries Station of Japan 1948-49), the hyrographical division of the Bay was ascertained and the mixing of coastal and oceanic waters was recognized at the junction of the two regions. The surface currents in Tokyo Bay are shown in Fig. 1 (Suda, 1929), and the distribution of average chlorinity of monthly observed data suggests the possibilities of the presence of these currents (Fig, 3 ).

From the vertical stability calculated and the isoplet diagram of chlorinity, it was estimated that the water of the inner part was thoroughly mixed from surface to bottom in winter. Annual variations in tempeature at different depths in the station 29 is shown in Fig. 4. In winter the water from surface to $50 \mathrm{~m}$. was thoroughly mixed and in summer the water below $100 \mathrm{~m}$. showed the lowest temperature. The latter fact may bedue to the upwelling of cold deep water. The remarkable increase of phosphate content may be assumed to support the presence of the upwelling.

The seasonal change in the average amount of phytoplankton collected at various

Recieved April 30，1953。（印刷整負进) 


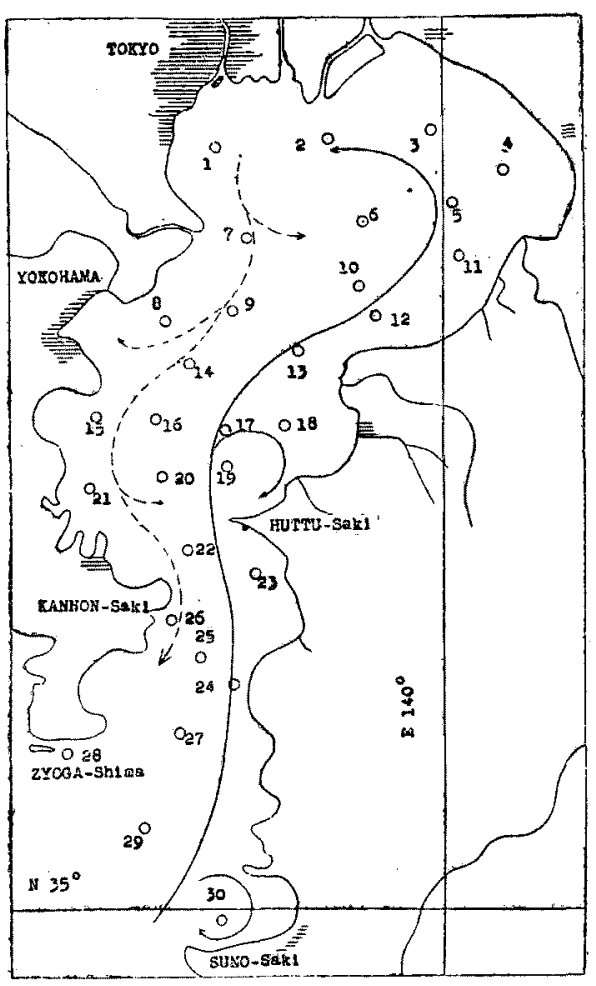

Fig. 1 Surface currents in Tokyo Bay. $O$ and number denote the observed station and station number, respectively.

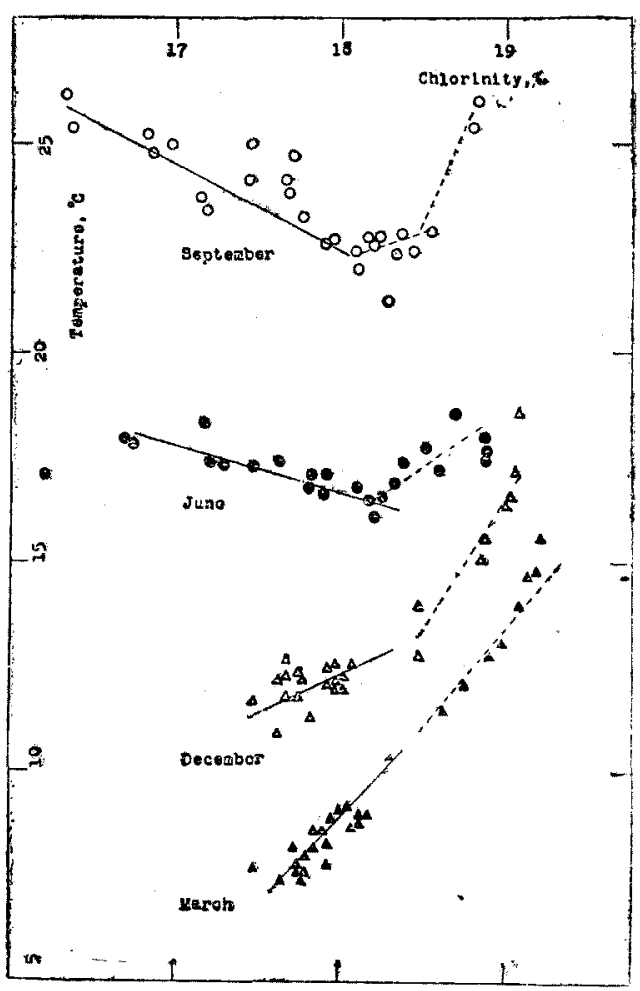

Fig. $2 \mathrm{~T}-\mathrm{Cl}$ diagram of $5 \mathrm{~m}$ layer in Tokyo Bay. Solid line denotes the inner part. Dotted line denotes the Uragacuido.

points in the inner part of the Bay is shown in Fig. 5. There should be some incerrelation between the seasonal changes in the amounts of plankton and that in the contents of nutrient salts. In the following paragraph, qualitative interpretations will be given on the seasonal changes and on cycles of nutrient elements.

\section{On the ratio of nitrogen and phosphorus.}

In the deep water of ocean the atomic ratio of nitrate nitrogen and phosphate phosphorus is 16:1 and the ratio of nitrogen and phosphorus in plankton is the same (Sverdrup, Johnson, and Fleming, 1942). Since in deep water almost all of nitrogen and phosphorus are in the forms of nitrate, and phosphate, it may be considered that the ratio of nitrogen and phosphorus in oceanic water wouldut pe $16: 1$.

The sum of nitrogen content in various forms and total phosphorus content in the water of the Bay were determined, because the coastal water contains abundant organic compounds. Some of which are containing nutrient elements. Some examples are shown in Tables 1 and 2. The results indicated that the mean ratio of nitrogen and phosphorus in the Bay is 7.4 (in weight), or 16 (in atom number), the confidence 


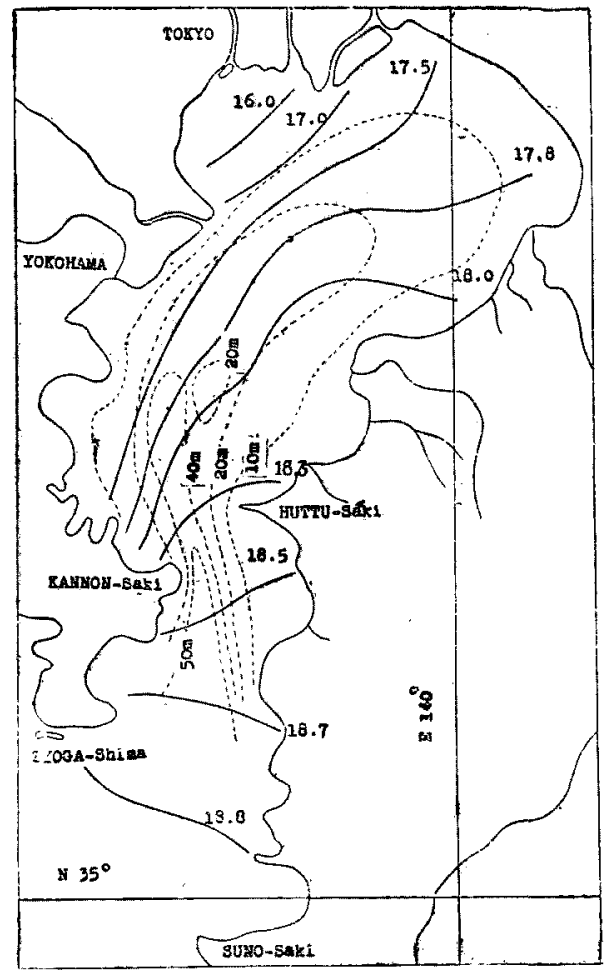

Fig. 3 The average distribution of chlorinity for all year round. Unbroken line denotes the isochlorinity line of surface. Broken line denotes the contour line of Tokyo Bay.

limits of the value being 8.5 and 6.3 in weight $(\alpha=0.05)$. In the case represented in Table 1 organic nitrogen was not detected but, on the other hand, $90 \%$ of phosphorus was found in organic matter.

2. The cycles of phosphorus and nitrogen in the inner part of Tokyo Bay.

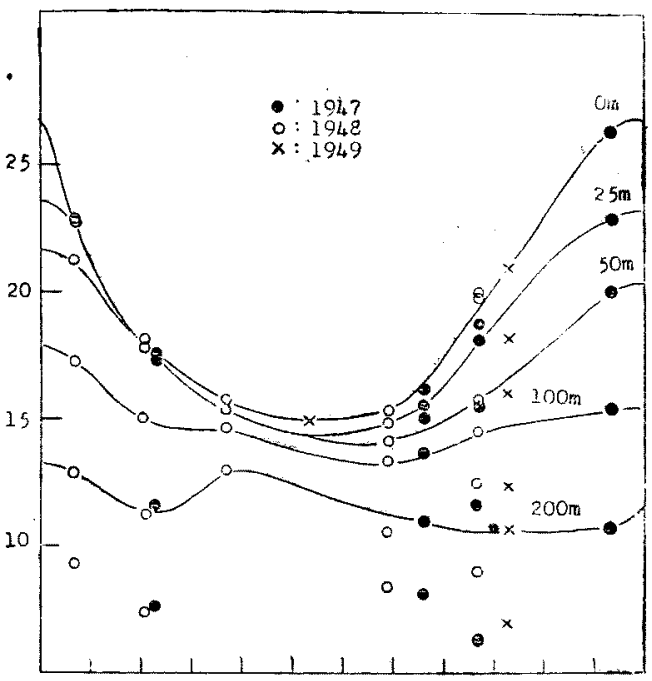

Oct Nov Dec Jan Feb MarApr May Jun Jul Aug Sep

Fig. 4 Annual variation in temperaturc at different depths in Uraga Suido.

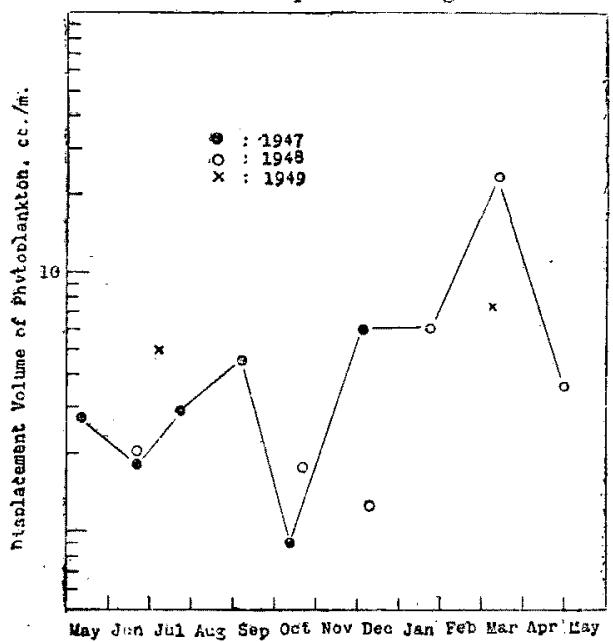

Fig. 5 Seasonal change in the amount of phytoplankton.

At. station Nos. 2, 5, 10,14, and 19, the annual changes in nitrogen, phosphate phosporus, the atomic ratio of total inorganic nitrogen * and phosphate phosphorus, and the atomic ratio of nitrate nitrogen and phosphate phosphorus are shown (Fig. 6). The values concerh the quantities in a water column under $100 \mathrm{~cm}^{2}$. suif $\mathrm{face}{ }^{\mathrm{k} * \mathrm{k}}$.

* Sum of nitrogen in nitrate, nitrite, and ammonium. Represented by $\Sigma N$.

** Analytical methods used in the present study were in accord with the ordinary methods (MIYAKE, 1949). 
Table 1. Contents of nitrogen and phosphorus. 1)

Unit: $r / 1$. Station : No.14. Date:Oct. 1949.

\begin{tabular}{r|c|r|r|r|r|r|r|r|r|r}
\hline $\begin{array}{c}\text { Depth } \\
\mathrm{m} .\end{array}$ & $\mathrm{NO}_{3}^{-}-\mathrm{N}$ & $\mathrm{NO}_{2}^{-}-\mathrm{N}$ & $\mathrm{NH}^{+}-\mathrm{N}$ & $\begin{array}{r}\text { Org. } \\
\mathrm{N}\end{array}$ & $\mathrm{PO}_{4}-\mathrm{P}$ & Org. ${ }^{3)}$ & $\sum \mathrm{N}$ & Tatal $\mathrm{P}$ & $\left.\mathrm{N} / \mathrm{P}^{3}\right)$ \\
\hline 0 & 195 & 6.0 & 150 & 0 & 4.0 & 66.0 & 351 & 70.0 & 5.0 \\
5 & 189 & 8.8 & 355 & 0 & 14.0 & 66.0 & 554 & 80.0 & 6.9 \\
10 & 290 & 14.7 & 299 & 0 & 9.8 & 67.2 & 600 & 77.0 & 7.8 \\
20 & 348 & 12.9 & 325 & 0 & 6.0 & 72.0 & 690 & 78.0 & 8.9 \\
32 & 410 & 10.8 & 105 & 0 & 14.4 & 60.6 & 530 & 75.0 & 7.1 \\
\hline
\end{tabular}

1) Mean of duplicate analysis.

2) Total phosphorus minus phosphate phosphorus.

3) N/ (Total phosphorus).

Table 2. Contents of various types phosporus.

Unit $: r / 1$. Station : No. 14. Date : Oct. 1919 .

\begin{tabular}{c|c|c|c|r|r|r|r}
\hline $\begin{array}{c}\text { Depth } \\
\text { m. }\end{array}$ & I & II & II & $\begin{array}{r}\text { N } \\
\text { I }\end{array}$ & V & V & W \\
\hline 0 & 70.0 & 70.0 & 70.0 & 4.0 & 66.0 & 0.0 & 0.0 \\
5 & 80.0 & 80.0 & 67.5 & 14.0 & 53.5 & 12.5 & 0.0 \\
10 & 77.0 & 77.0 & 69.1 & 9.8 & 59.3 & 7.9 & 0.0 \\
20 & 78.0 & 76.3 & 72.5 & 6.0 & 66.5 & 3.8 & 1.7 \\
32 & 75.0 & 75.0 & 75.0 & 14.4 & 60.6 & 0.0 & 0.0 \\
\hline
\end{tabular}

I : Untreated sample.

II : Filtered through Toyo $5 \mathrm{C}$ filter paper.

1. Filtered through a sintered glass filter, inside coated with $3 \%$ collodion.

$\mathrm{V}$ : Total-P (豆) minus $\mathrm{PO}_{1}$ " $-\mathrm{P}$.

VI :Total-P (II) minus Tatal-P ( II ).

VII : Total-P (I) minus Total-P (I).

From Fig.6, the following phenomena were observed: (1) The contents of nitrate and phosphate reached a minimum in spring on the contrary the maximum growth of phytoplankton was shown in spring. The station No.2, located near the mouths of rivers, was exceptional. (2) The ratio of nitrate nitrogen and phosphate phosphorus showed a minimum in spring. (3) The ratio of total inorganic nitrogen and phosphate phosphorus showed a maximum in spring.

If the ratio of the absorption velocities of nitrogen and phosphorus by phytoplankiton is $16: 1$ in atom number, and if the velocity of the regeneration of phosphate is slower than that of inorgananic nitrogen, $\Sigma N$, the ratio of $\Sigma N$ and phosphate phosphorus may become maximum in spring. If it is also assumed that nitrate nitrogen is selectively consumed by phytoplankton, and further, that the oxidation of nitrogen decrease during winter to early spring, the minimum in the ratio of nitrare nirrogen and phosphate phosphorus in spring may be explainable.

3. Some remarks on the distributions of nitrate and phosphate in summer.

The contents of nitrate, nitrite, ammonium, and phosphate at each station were 


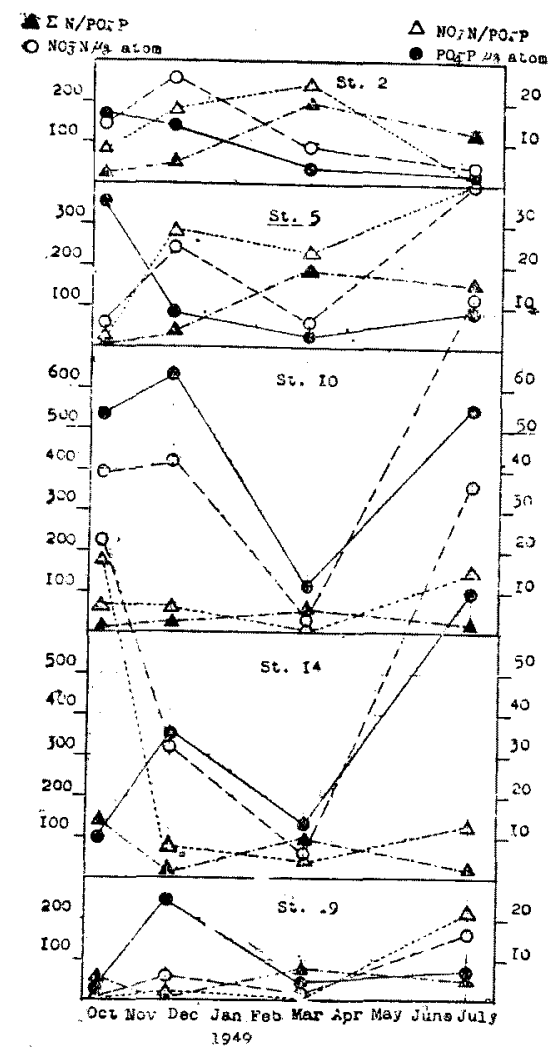

Fig. 6 Annual changes in the contents of nutrient Salts. determinad in July 1048. The results are shown in Fig. 7. The lines $A$ and $B$ are expressed by the following equation:

$$
\begin{aligned}
& \log \left(\mathrm{NO}_{3}^{-}-\mathrm{N}\right) /\left(\mathrm{PO}_{4}{ }^{-}-\mathrm{P}\right) \\
& \quad=\mathrm{a}+\mathrm{b} \times \log (\Sigma \mathrm{N}) /\left(\mathrm{PO}_{4}{ }^{{ }^{-}}-\mathrm{P}\right),
\end{aligned}
$$

where $\mathrm{a}$ and $\mathrm{b}$ represent constants.

The fact that nearly all of open circles (O) in Fig. 7 located on the light side of the line

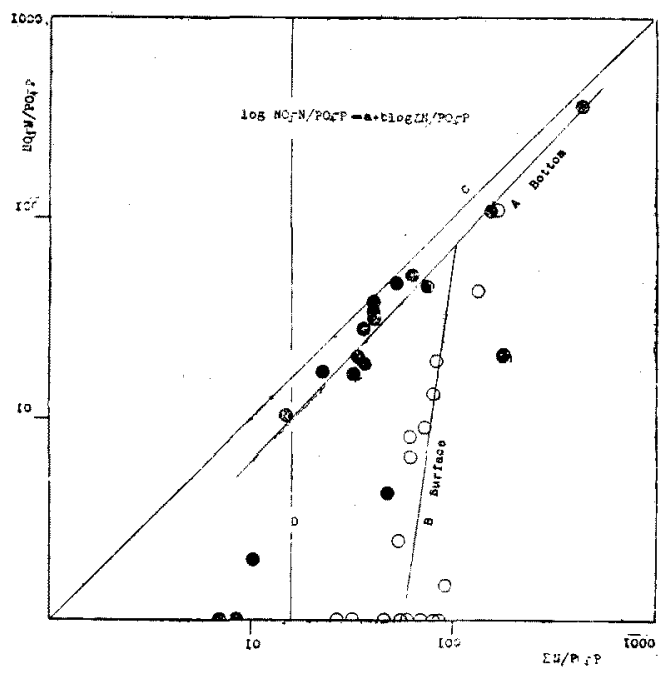

Fig. 7. The relaion between $\mathrm{NO}_{3} \mathrm{~N} / \mathrm{PO}_{4}-\mathrm{P}$ and $\Sigma N / \mathrm{PO}_{4}-\mathrm{P}$ \&f surface and bottom layers in summer.

$\mathrm{D}$ which represents the relation $\Sigma N / \mathrm{PC} \equiv-\mathrm{P}=16$ indicates that in the striface layer inorganic nitrogen phosphate phoshorus ratio is larger than 16 in atom number at every station. Distriburion of nearly all of the solid circles ( ) along the $\mathrm{C}$ line which represents the relation $\sum N=\mathrm{NO}_{3}^{-}-\mathrm{N}$, and on the light side of the line $\mathrm{D}$ indicates that in bottom layer (1) nearly all nitrogen exits as nitrate and (2) $\sum N$ is larger than the value calculated by veing the relation $\mathrm{N} / \mathrm{P}=16$. This fact may be explained by assuming that only decomposition or oxidation of the matter containing nitrogen and phosphorus takes place in the bottom layer and by assuming that the regeneration velocity of inorganic nitrogen is larger than that of phoshate*.

In the surface layer, the ratio of nitrate nitrogen and phosphate phosphorus was less than 16, while the ratio of $\sum N$ and phosphate phosphorus was larger than 16. It may be reasonable to consider that the former fact suggets the selective consumption

* In the coastal region, precipitation of fhosphorus with mud should be considered. 
of nitrate and the latter, the regeneration velocity of nitrogen is higher than that of phosphate.

The tangent of line B in Fig. 7 is larger than that of line A. This may be due to higher oxidation velocity of nitrogen in the surface layer than in the bottom layer.

The term $\left(\mathrm{PO}_{4}=-\mathrm{P}\right)$ in the equation of line $\mathrm{B}$ could not be cancelled, because the tangent $\mathrm{b}$ was not equal to unity. This may suggest that phosphate is necessary in the assimilation of nitrogen by phytoplankton. Then, in the study of the assimilation of nitrogen by phytoplankton, the interaction of nitrogen and phosphorus should be taken into consideration. The writer wishes to express his heartfelt thanks to Dr. M. Migita, Dr. Y. Miyake, and Dr. T. Hanaoka for their valuable criticisms and suggestions. Especially must the writer express his gratitude to Prof. M. Tauchi and Prof. H. Goto for their encouragements in the course of this work.

\section{References}

Central Fisheries Station of Japan, [Report of Oceanographical Observations of Tolsyo Bay], $(1948-49)$.

Y. MiYake, ["Water Analysis (Japanese)"], (1949). Tokyo.

K. SudA, J. Oceanogr. Imp. Observ., Kobe, Japan, 3 (1929).

H. U. Sverdrdp, M.W. Johnson and R. H. Fiemina, "Oceans, Their Physics, Chemistry and" General Biology", pp. 234-246 (1942). New York. 